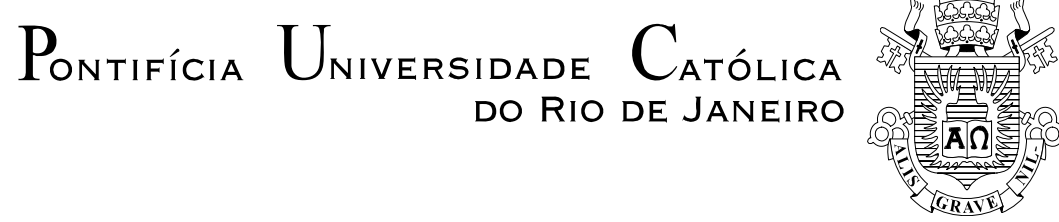

Carolina Scali Abritta

\title{
A CONSTRUÇÃO DO ACORDO EM RELAÇÕES DE CONSUMO. UM ESTUDO DE AUDIÊNCIAS DE CONCILIAÇÃO
}

\section{Tese de Doutorado}

Tese apresentada ao Programa de Pós-graduação em Letras do Departamento de Letras da PUC-Rio como parte dos requisitos parciais para obtenção do título de Doutor em Letras.

Orientadora: Profa. Maria do Carmo Leite de Oliveira

Rio de Janeiro

Dezembro de 2011 


$$
\begin{array}{r}
\text { Pontifícia Universidade Católica } \\
\text { do Rio de Janeiro }
\end{array}
$$

Carolina Scali Abritta

\title{
A CONSTRUÇÃO DO ACORDO EM RELAÇÕES DE CONSUMO. UM ESTUDO DE AUDIÊNCIAS DE CONCILIAÇÃO
}

\begin{abstract}
Tese apresentada como requisito parcial para obtenção do grau de Doutor pelo Programa de Pós-Graduação em Letras do Departamento de Letras do Centro de Teologia e Ciências Humanas da PUC-Rio. Aprovada pela Comissão Examinadora abaixo assinada.
\end{abstract}

\author{
Profa. Maria do Carmo Leite de Oliveira \\ Orientadora \\ Departamento de Letras - PUC-Rio
}

Profa. Liliana Cabral Bastos

Departamento de Letras - PUC-Rio

Profa. Sonia Bittencourt Silveira

UFJF

Profa. Wânia Terezinha Ladeira

UFV

Prof. Paulo Cortes Gago

UFJF

Profa. Denise Berruezo Portinari Coordenadora Setorial do Centro de Teologia

e Ciências Humanas - PUC-Rio

Rio de Janeiro, 21 de dezembro de 2011. 
Todos os direitos reservados. É proibida a reprodução total ou parcial do trabalho sem autorização da universidade, da autora e da orientadora.

\section{Carolina Scali Abritta}

Graduou-se em Direito pela Faculdade de Ciências Jurídicas e Sociais Vianna Jr. em 2003 e em Letras pela Universidade Federal de Juiz de Fora em 2005. Fez mestrado em Letras Linguística - naquela universidade federal e, em 2008, ingressou no curso de Doutorado em Letras da PUC-Rio. Participa do grupo de pesquisa do CNPq: "Discurso, Interação e Trabalho”.

Ficha Catalográfica

Abritta, Carolina Scali

A construção do acordo em relações de consumo: um estudo de audiências de conciliação / Carolina Scali Abritta; orientadora: Maria do Carmo Leite de Oliveira. 2011.

170 f. ; $30 \mathrm{~cm}$

Tese (doutorado) - Pontifícia Universidade Católica do Rio de Janeiro, Departamento de Letras, 2011.

Inclui bibliografia

1. Letras - Teses. 2. Mediação. 3. Relações de consumo. 4. Cidadania. 5. Personalismo. 6. Apresentação do self. 7. Face. 8. Papel. I. Oliveira, Maria do Carmo Leite de. II. Pontifícia Universidade Católica do Rio de Janeiro. Departamento de Letras. III. Título. 
Para meu pai e minha mãe (saudades), dos quais herdei o gosto pelas Letras e pelo debate de ideias. Com todo o meu amor e a minha eterna gratidão. 


\section{Agradecimentos}

Mário Quintana define assim as utopias:

Se as coisas são inatingíveis... ora! não é motivo para não querê-las...

Que tristes os caminhos, se não fora a mágica presença das estrelas!

Muitas pessoas viram neste trabalho uma estrela e me apontaram caminhos para que eu pudesse contemplá-los mais de perto - o trabalho e a estrela.

Uma das primeiras foi sem dúvida a minha orientadora querida, Maria do Carmo Leite de Oliveira. Tratá-la simplesmente por orientadora é aqui apenas um sinal de respeito ao tom formal deste texto. Ela foi, durante todo esse trajeto, muito mais do que isso: foi uma amiga que muitas vezes me lembrou de que "Deus ao mar o abismo e o perigo deu/ Mas nele é que espelhou o céu" (Fernando Pessoa). A aventura da pesquisa ao seu lado e todos os riscos nela envolvidos ficaram sempre minimizados por ter tido a presença de pessoa de tamanha sabedoria e bondade ao meu lado. A aventura da vida perto dela também pareceu mais suave, uma vez que sempre levou em conta a possibilidade de se contemplar o céu no mar após um período de turbulência. Os agradecimentos serão sempre pouco neste caso.

A Professora Sonia Bittencourt Silveira também sempre esteve ao lado em todos os momentos deste trabalho. Aliás, acompanha minha trajetória desde os tempos da Iniciação Científica incentivando de maneira ímpar minhas pesquisas, vendo de perto o desenvolvimento e as conclusões, compartilhando de maneira generosa seus conhecimentos e seu olhar arguto para os dados. Ela também muito, muito mais do que uma orientadora de IC e de mestrado, muito mais do que uma examinadora constante desta pesquisa, fez-se sempre uma amiga do trabalho e da vida. As palavras serão sempre muito pouco aqui também para agradecer.

A Professora Wânia Ladeira também acompanha já há muito tempo meus estudos e, mais do que isso, cedeu seus próprios dados para esta pesquisa, que se iniciou no mestrado e teve continuação no doutorado. Sou-lhe grata por isso e pela amizade que se formou entre nós. Tê-la agora olhando esta análise de perto é uma honra para mim.

O Professor Paulo Gago também olha há tempos para minhas investigações, acompanhando-me desde o mestrado, quando tive a oportunidade de ser sua aluna. O olhar de Analista da Conversa, tão importante para fixar os pés nas estruturas interacionais emergentes, não foi, porém, sua única marca deixada aqui. Nos encontros de grupo de estudo que fizemos em sua casa e na da minha 
orientadora querida, muitos deles na companhia da Professora Sonia, as discussões teóricas ali travadas também surgiram como placas indicadoras de caminhos aqui.

A Professora Maria Claudia Coelho apontou-me a via da Antropologia que se cruza com os estudos da linguagem e do direito e que se faria fundamental para a caminhada desta investigação.

A Professora Liliana Cabral Bastos mostrou-me, logo no início do doutorado, pontes com a Linguística muito interessantes, através de referências bibliográficas, e também me apontou um trajeto que iria ao encontro do trabalho do grande antropólogo Gilberto Cardoso Velho. Foi no curso dela que pude ter o primeiro contado com leituras deste intelectual e foi também ali que me despertei para frequentar uma disciplina no Museu Nacional ministrada pelo próprio Prof. Dr. Gilberto Velho.

Aquele semestre no Museu, os ensinamentos daquela disciplina sobre Antropologia das Sociedades Complexas, com certeza, deixaram marcas profundas no meu olhar para as interações sociais. Sou grata ao Professor Gilberto por ter-me aceito e pacientemente muitas vezes ouvido. Sou lhe grata também pelas palavras sobre minha pesquisa que lhe apresentei naquela ocasião.

Aqui jamais poderia esquecer-me da Professora Maria das Graças Dias Pereira e do ótimo curso sobre as relações entre linguagem, cultura e identidade por ela ministrado na PUC. Impossível não lembrar da capacidade dela de concentração de referências bibliográficas relevantes naquele curso.

Também preciso agradecer à Chiquinha que, muito mais do que ajudar com as burocracias secretariais, foi de suma importância para encontrar uma bolsa de agência de fomento que financiasse essa pesquisa.

Por isso, agradeço também ao CNPQ, pelo financiamento concedido.

Por fim, last but not least, agradeço aos meus amores: meu marido, meu pai, meus irmãos, Tati e Dani, e meu cunhirmão, Fred. O incentivo, o carinho, a confiança, a compreensão e principalmente o amor de todos foi sempre um combustível essencial para por em movimento este trabalho. Todos são, com certeza, estrelas na minha vida. 


\section{Resumo}

Abritta, Carolina Scali; Oliveira, Maria do Carmo Leite (Orientadora). A Construção do Acordo em Relações de Consumo. Um Estudo de Audiências de Conciliação. Rio de Janeiro, 2011. 170p. Tese de Doutorado - Departamento de Letras, Pontifícia Universidade Católica do Rio de Janeiro.

O presente trabalho teve por objeto a investigação e análise de audiências de conciliação envolvendo lides de consumo. O corpus foi composto por seis audiências gravadas e transcritas na íntegra. O objetivo geral do estudo foi o exame dos modos de apresentação do self projetados pelas partes, assim como das faces atribuídas e reivindicadas pelas mesmas e dos papéis co-construídos. No entanto, o objetivo específico foi ver como essas categorias analíticas se mostravam relevantes para a tomada do acordo. Uma vez eleita esta última meta, apenas três audiências foram analisadas verticalmente, posto que só aquelas com acordo interessavam ao estudo. Essas audiências foram segmentadas e descritas em fases - desde o relato até a reparação do dano através do termo do acordo. Uma fase, entretanto, interessou mais a este trabalho. Trata-se da fase da proposta resolutória, em que o mediador tenta chegar a uma proposta comum para reclamante e reclamado. Neste momento interacional, o papel do mediador se mostrou central. As faces construídas e as apresentações de self dos demais interagentes emergiram como projeção do mediador ou como contraponto ao que era por ele estabelecido. Na análise pormenorizada de cada audiência, verificou-se a emergência de formatos de papel fundamentais à tomada do acordo. Um destes formatos foi o da cidadania, através do qual a mediadora desempenhou o papel de intérprete e aplicadora da lei. O outro formato foi o do personalismo, em que a mediadora desempenhou um papel de facilitadora do acordo. Neste último caso, um diálogo com teorias antropológicas sobre o Brasil fez-se imprescindível para a compreensão do aqui e agora interacional. A categoria do jeitinho emergiu como estratégia para garantir o acordo e até mesmo o exercício do direito.

\section{Palavras-chave}

Mediação; Relações de consumo; Cidadania; Personalismo; Apresentação do self; Face. Papel. 


\section{Abstract}

Abritta, Carolina Scali; Oliveira, Maria do Carmo Leite (Advisor). The agreement construction in consumer relations. A study of conciliation hearings.. Rio de Janeiro, 2011. 170p. Ds. Thesis - Departamento de Letras, Pontifícia Universidade Católica do Rio de Janeiro.

The present work aims at investigating and analyzing conciliation hearings which involve consumption conflicts. The data is composed by six hearings entirely recorded and transcribed. The overall objective of this study was to evaluate the forms of presentation of self projected by the parties, as well as of faces assigned and claimed by them and their co-constructed roles. However, our specific objective was to see how these analytical categories would appear relevant to the agreement-making process. Once this last aim had been established, we analyzed just three hearings, since we were only interested in those where an agreement had been reached. Those hearings were divided and described in phases - from the report until the action for damages as established by the agreement. One phase, however, seemed to be more interesting to this study. It was the resolutory proposal phase, in which the mediator tried to establish a common proposal for both responded and complainant. In this interactional moment, the mediator's role was of utmost importance. The constructed faces and the presentations of the other interactants' selves emerged as a projection of the mediator or as a counterpoint to what had been established by him/her. In the detailed analysis of each hearing, we have observed the emergence of role formats essential to the agreement-making process. One of these formats was that of citizenship, through which the mediator played the role of spokeswoman and law enforcer. The other form was that of personalization, in which the mediator played the role of an agreement facilitator. In this last case, a dialogue with anthropological theories about Brazil was indispensable to the understanding of the interactional here and now. The category of "jeitinho" has emerged as a strategy to secure the agreement and even the practice of law.

\section{Keywords}

Mediation; Consumer relations; Citizenship; Personalization; Presentation of self; Face. Role. 


\section{Sumário}

\section{Introdução}

2. Pressupostos Teóricos

2.1. Construção de Relações Pessoais e Estudos de Face

2.2. A Elaboração da Face em Goffman ([1955] 1980)

2.2.1. Tato e Interação: elaborando faces

2.2.2. A face como construto da apresentação do self

2.2.3. A face como construto interacional: por uma interpretação menos restrita do trabalho de Goffman

2.3. Papel, Identidade e Face: superposições conceituais e especificidades

2.4. Tipo de Atividade, Face e Papel: a interdependência situacional

2.5. Face, Cultura e Questões Brasileiras

2.5.1. A dependência cultural da noção de face

2.5.2. Por uma visão de cultura como contexto - o ponto de vista de Geertz

2.5.3. As várias faces da cultura brasileira, contribuições antropológicas: personalização de relações, jeitinho e favor

2.5.3.1. As noções de indivíduo e pessoa em Roberto DaMatta

2.5.3.2. A construção de relações pessoais - o uso do jeitinho para conseguir um favor

2.5.3.3. Sistemas de troca de favores e construção de relações pessoais: as semelhanças entre o blat, o ganxi e o jeitinho.

\section{Pressupostos Metodológicos}

3.1. A Natureza qualitativa e interpretativista da Pesquisa

3.1.1. O paradoxo do analista: por uma perspectiva analítica dos participantes

3.2. A Seleção e o Tratamento dos Dados

3.2.1. A opção por dados gravados de fala

3.2.2. O uso de informações de base etnográfica

3.2.3. A escolha das audiências, a seleção das sequências interacionais e a análise em pares - contribuições da Análise da Conversa Etnometodológica

\section{Análise dos Dados}

4.1. Banco Sul: fases de uma audiência de conciliação, o exercício da cidadania e as marcas do personalismo via jeitinho

4.1.1. As fases finais da audiência: a fase da proposta resolurória e a fase da concretização do acordo

4.2. Ok! Veículos: o jeitinho na fase da proposta resolutória - o lado mais negativo desse fenômeno cultural

4.3. Blóquia: o jeitinho e o favor na construção de uma proposta resolutória de acordo 
5. Considerações Finais

5.1. Resumo dos Resultados

99

5.2. Contribuições e Limitações da Pesquisa

106

Referências bibliográficas

109

Anexos

116 